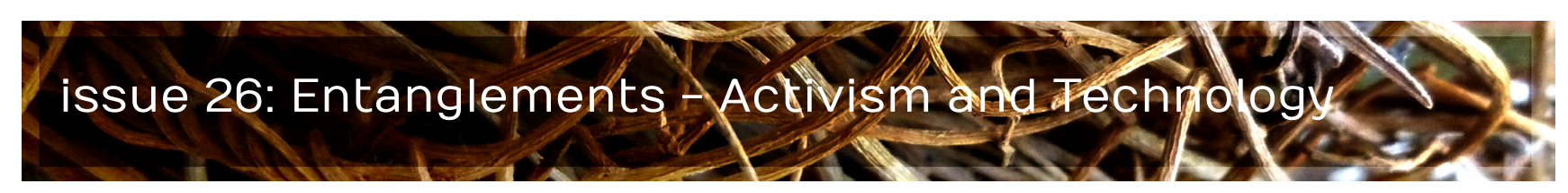

\title{
FCJMESH-007 Our Enduring Confusion About the Power of Digital Tools in Protest
}

\author{
Ivan Sigal and Ellery Biddle \\ Global Voices
}

\begin{abstract}
Since 2005 Global Voices has supported thousands of writers, online media experts and translators to share stories across borders and languages. Many of these stories have covered digital activism and protest around the world. In this article Ivan Sigal and Ellery Biddel share what they've learnt about protests, tipping points and technologies by reflecting on these stories and on the contrary narratives about these events that mainstream media have tended to focus on.
\end{abstract}

doi: 10.15307/fcj.mesh.007.2015

Did technology $X$ spark revolution $Y$ ? Pundits and political leaders have pointed to or blamed social media for driving the uprisings in the Arab region and for many other mass protests around the world, including those in the Philippines and Korea at the beginning of the century, as well as more recent uprisings in Burma, Moldova and Iran. In each case, it is clear that social media platforms have played a vital role in expanding the reach of communications and in helping like-minded activists to meet. It is equally clear that without the networks of activists who have worked together for years, laying the foundation for this groundswell, together with the convergences of many other social and political forces, each of these uprisings would either not have occurred or not have been sustained. 
At Global Voices, we cover stories that are not well represented in global media but are important to local communities. Our advocacy work focuses on online freedom of expression and governmental and corporate restrictions on the ability of individuals to speak, to listen, and access information. We also cover evolving stories of digital activism and protest around the world.

Over the past 10 years, the work of Global Voices has concentrated on eruptions of resistance to state and corporate authority within networked publics. Networked publics are communities of individuals for whom an overlay of telecommunications and Internet connectivity facilitates multiple, diverse links across time and space.

Since 2005 Global Voices authors have written more than 9,600 stories about protest, and nearly 10,500 stories about digital activism around the world. Additionally, we've created more than 60 special coverage sections that focus on digital activism, occurring in more than 40 countries. Many of the stories of digital activism and protest overlap, forming a body of material that gives us a rich picture of the relationship between digital technologies and their use in creating or supporting protest movements. These stories together form a set of data about emerging forms of protest and resistance, evolving tactics in the use of technology for protest and over time, a sense of the power dynamics that underlie these networks of individuals who coalesce around a range of political and social causes, many of which involve some form of assertion of rights.

Through this work we have found that groups of activists are aware of movements that have preceded them and are able to learn from their tactics, failures and successes in applying technology to their causes. Learning from other movements has led many activists to seek technology solutions that are both simple and widely available-cell phones, texts, email lists, cloud-based shared documents and popular social media platforms such as Facebook and Twitter, as well as older communication methods such as radio, pamphlets and word-of-mouth. And yet, the narrative of diverse communications choices rarely appears in mainstream media analyses; instead media coverage all too often emphasises new technology as the magic bullet that enables protests or mass uprisings. This misunderstanding shifts focus from the value of the protesters and the possible validity of their grievances onto a narrower story about the capabilities of new communications technologies.

After observing many protest movements over time at Global Voices, we can see a framework emerging that supports a richer understanding of the role that networked publics play in creating and supporting activism. We can see that protests will occur 
wherever networks of individuals are able to coalesce around a grievance and find symbols under which to organise. In 2011 we saw the Arab uprisings, crises protests in Europe and the Occupy movement; 2014 brought us protest movements in Ukraine, Venezuela, Taiwan, Mexico, and Hong Kong. This eruption of mass protests does not mean that the grievances were similar, or that the movements themselves necessarily had much in common in terms of strategy, goals or culture. Rather, the point is that the acceleration function of networks helps individuals find and learn from one another and to develop common causes.

Often utopian thinking espousing the power of technology obscures the stories that lie at the roots of a movement. Yet, observing dozens of protests emerge through reports at Global Voices we have seen something else happening. While we cannot predict the set of conditions which will lead a country to become the focus of future resistance and protest, we can recommend looking for the spark of resistance within networks of publics. Often, we have observed, that it is an event that occurs on the margins that serves as a catalyst, before becoming a symbol for a protest: often this symbol is human, charged with emotion and historically resonant.

The Tunisian revolution was lit by the match of the self-immolating Mohamed Bouazizi in the provincial town of Sidi Bouzid. Brazil's 2013 Vinegar Revolt was set off by a rise in public transport fees; but it was the vinegar that people used to endure tear gas that became the symbol of that movement. In short, the spark of protest is often an affect-shared and collective emotive responses to a piece of evidence about human consequences and emotions-rather than an effect, or a logical chain of reasoned argument. In this way we have learnt that it is the human, story-driven elements that bring people together to protest or create movements.

This is not to assert that technology is irrelevant or insignificant in recent mass protests and uprisings. Over the past several years we've seen the rise of mobile technology applications designed to serve activist ends, with affordances of anonymity, anti-surveillance, documentation and forensics, and management of evidentiary chains, such as the carefully considered applications created by the Guardian Project. Yet these tools can take years to develop and often serve narrow user groups of human rights activists, journalists and researchers. Their use in the context of mass protest requires either that enough protesters are aware of or learn to use the tools in time to be useful during events, or shortly thereafter. Some of these tools can be very effective, but many have never been widely adopted or effectively used in protest and advocacy contexts. 
Despite this, it seems as if with every protest or revolt a new technology receives glowing press coverage as the latest solution du jour. Often the technologies touted were not designed for protest environments and are not secure; yet the media's promotion of their value may drive further use. The overblown hype around the network encryption tool Haystack during the Iranian protests in 2009 may have been the apex of this misguided focus. Ironically, the lack of a technology's security combined with promotion of its use may create a hazard where none existed, as governments find new ways to surveil activist communities and where activists identify themselves through their use of these technologies.

Over time we see the emergence and repetition of a key tension: an ongoing mismatch between technologies and their application. On the one hand, we experience the often difficult and slow development of specialised tools that don't reach wide adoption. On the other hand, we endure reckless promotion of inappropriate and unsafe tools. Finally, this occurs amidst a misplaced emphasis on technology over the stories, symbols and concerns that spark and sustain activism.

In 2014-during the Umbrella Protests in Hong Kong-we saw a flurry of discussion about the use of the Bluetooth chatroom tool Firechat. As demonstrations peaked in early October, the Guardian newspaper's Archie Bland mused that '[e]very major display of social unrest these days seems to come with a game-changing technological accompaniment.' He went on to explain how Joshua Wong, the 18-year-old described as the "leader" of the Hong Kong protests had urged protesters to use FireChat, a chatroom app that is bluetooth-based and can thus be used when the mobile networks are overloaded or shut down. Bland went so far as to suggest that protesters may have identified with the infrastructural details of the app itself: 'The protesters may find something satisfying in the way the system works, gaining strength like a movement, or a radical idea, not through a top-down imposition, but from thousands of little connections (Bland, 2014).' According to Firechat, the app garnered nearly 100,000 downloads at the height of the protests. In the end very few people used the app, and despite fears to the contrary, mobile networks were never shut down.

While the bulk of the Global Voices coverage of the Hong Kong protests focused on the experiences of those who led the demonstrations, we felt the need to offer a critical view of FireChat. We were motivated by the amount of attention and interest it seemed to garner online-particularly in the digital activist community-but we knew the Hong Kong government was unlikely to shut down mobile networks. We also knew that the app's weak security standards could actually increase protesters' vulnerability to surveillance. We connected our contributors in Hong Kong with security experts familiar with the technology. 
Together they produced a story that identified the use of Firechat as a potential threat to protesters.

In Venezuela, the walkie-talkie app Zello was briefly in the spotlight in 2014. During protests in Caracas in February 2014, Zello reported more than 15,000 downloads in a single day. It was then promptly blocked, but only after President Madura announced that the government was monitoring protesters by intercepting communications sent using Zello.

These examples also show us that when commercial technologies are used to support mass protests, there's a power exchange between user and company. Products like Zello, FireChat, and Haystack benefit from the notoriety of being depicted as the tool of choice for protests. When they then reach out to protesters to encourage use, they are both asserting and bestowing power.

In these cases, and many others like them, we aim to dispel the notion that the success or failure of a protest movement hinges on the use of a particular technology. While it is easy to find articles about technology use and colourful umbrellas in mainstream western coverage of the Hong Kong protests, this focus downplays the fact that this movement is actually about people's demands for universal voting rights. Too often, the medium or the platform or the tool distracts mainstream media. In so doing, they lose sight of the message of the movement: the idea or grievance that's brought everyone together in the first place. In highlighting a single, highly touted tool or turnkey communications solution they obscure the fact that in protest we see that the use of diverse and often simple communications solutions provide movements with the resilient and reliable tools that serve their ends.

Beyond the debate about tools, we should refocus our attention on mass protests as events that form out of collective affect and produce symbols that represent the grievances and goals of the protesters. Too often, the human, story-driven elements that bring people to protest or create movements are not prioritised in media coverage. The long-term work of activists who have been fighting for their own and other's rights often struggle to 
identify and sustain those symbols and to turn them into real-world change. Technology can often serve them, but these activists are done a great disservice by the highlighting of technology over their realities, efforts, stories, and needs.

\section{Author Biographies}

Ivan Sigal is the executive director of Global Voices, a non-profit online global citizen media initiative and he supports similar projects around the world. He is a fellow at the Berkman Center for Internet \& Society at Harvard University, where he studies digital storytelling and online communities. He is a media producer who works on long-term photography, multi-media and writing projects. He is the author of White Road (Steidl, 2012), based on eight years of photography and writing about Central Asia and Russia. Ivan spent over ten years in the former Soviet Union and Asia, where he designed and ran dozens of media projects focusing on conflict, humanitarian disaster and transitional societies.

Ellery Roberts Biddle is the Advocacy editor of Global Voices where she facilitates a network of bloggers and advocates dedicated to reporting on threats to online speech, sharing tactics for defending the digital work and words of citizens and supporting efforts to strengthen Internet policy and practice worldwide. An expert on digital culture in Cuba, Ellery has worked as a policy analyst and human rights advocate in the digital rights field since 2010. Ellery is currently fellow at the Berkman Center for Internet \& Society at Harvard University, where she is continuing her writing and research on technology and the informal economy in Cuba.

\section{References}

Bland, Archie. 2014. 'FireChat - the messaging app that's powering the Hong Kong protests', The Guardian, Tuesday 30 September (2014), http://www.theguardian.com/ world/2014/sep/29/firechat-messaging-app-powering-hong-kong-protests 
The LOCKSS System has the permission to collect, preserve and serve this open access Archival Unit

This Isuue of the Fibreculture Journal by The Fibreculture Journal Incorporated is licensed under a Creative Commons Attribution 4.0 International License.

\section{OPEN HUMANITIES PRESS}

The Fibreculture Journal is published by The Fibreculture Journal Incorporated in partnership with Open Humanities Press. 